
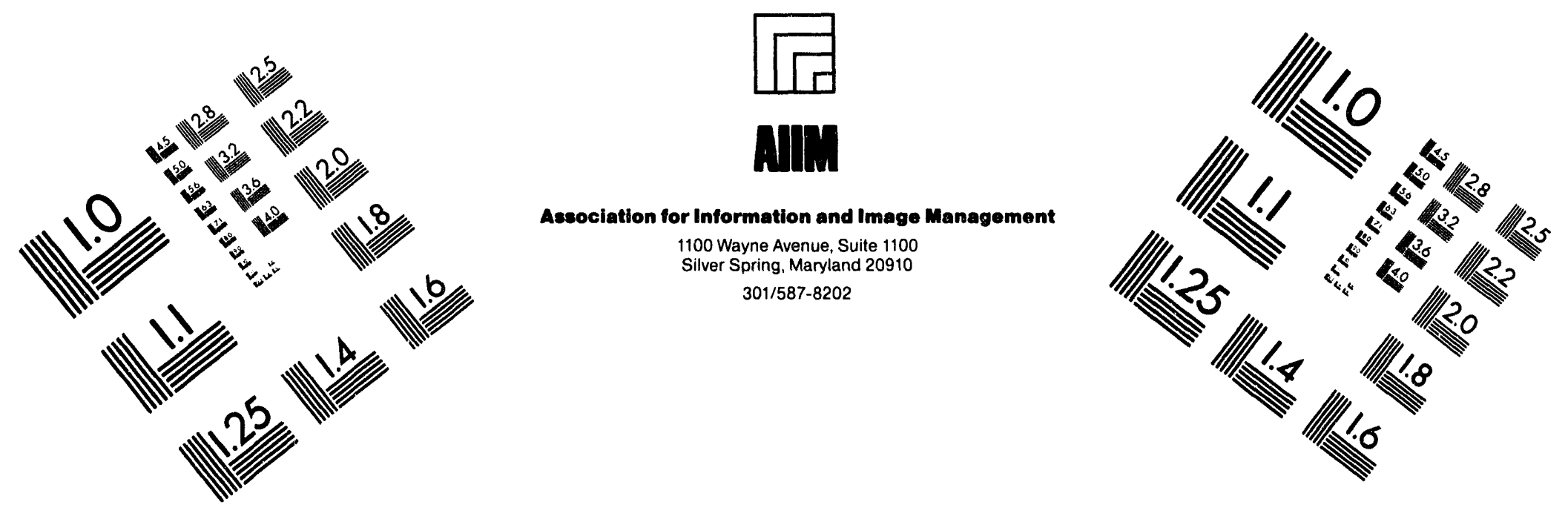

\title{
Centimeter
}

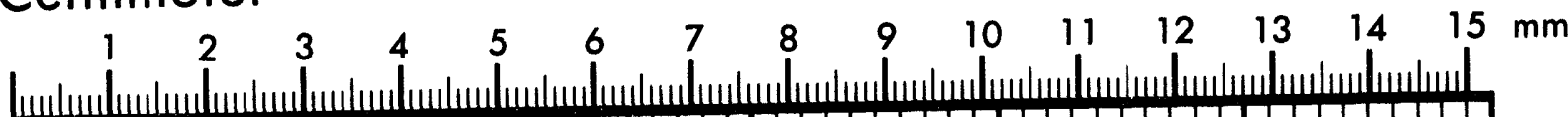

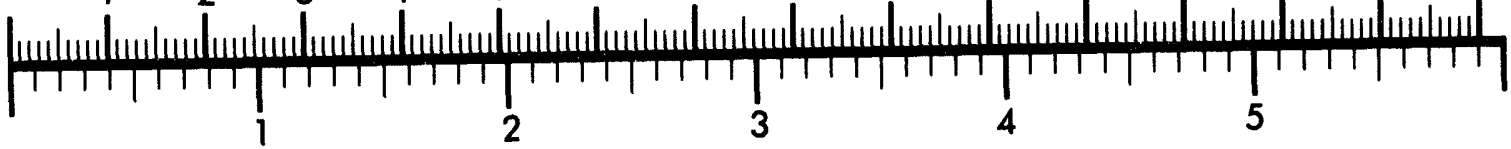
Inches
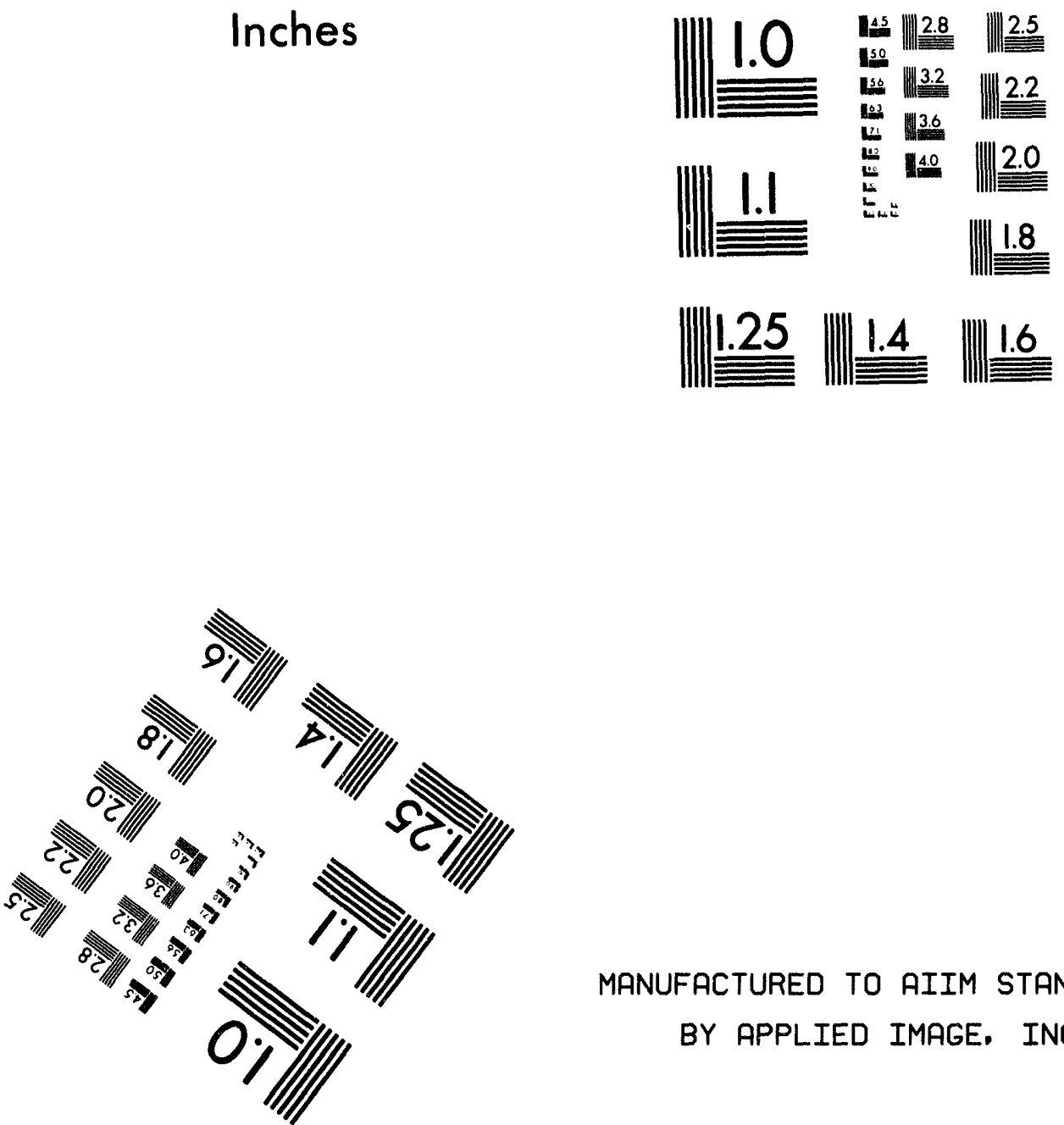

MANUFACTURED TO AIIM STANDARDS

BY APPLIED IMAGE, INC.

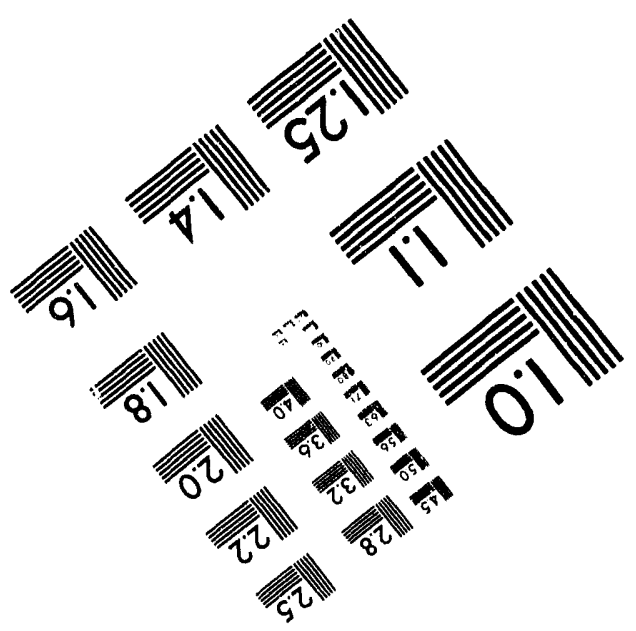



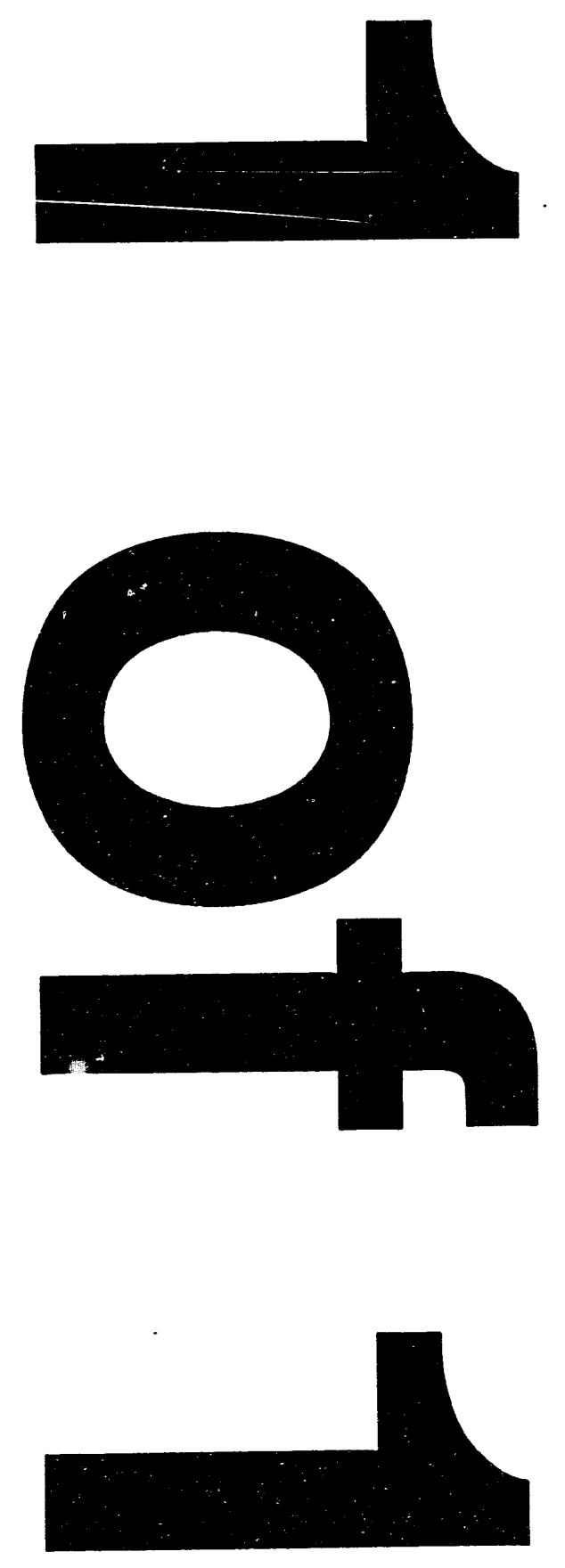


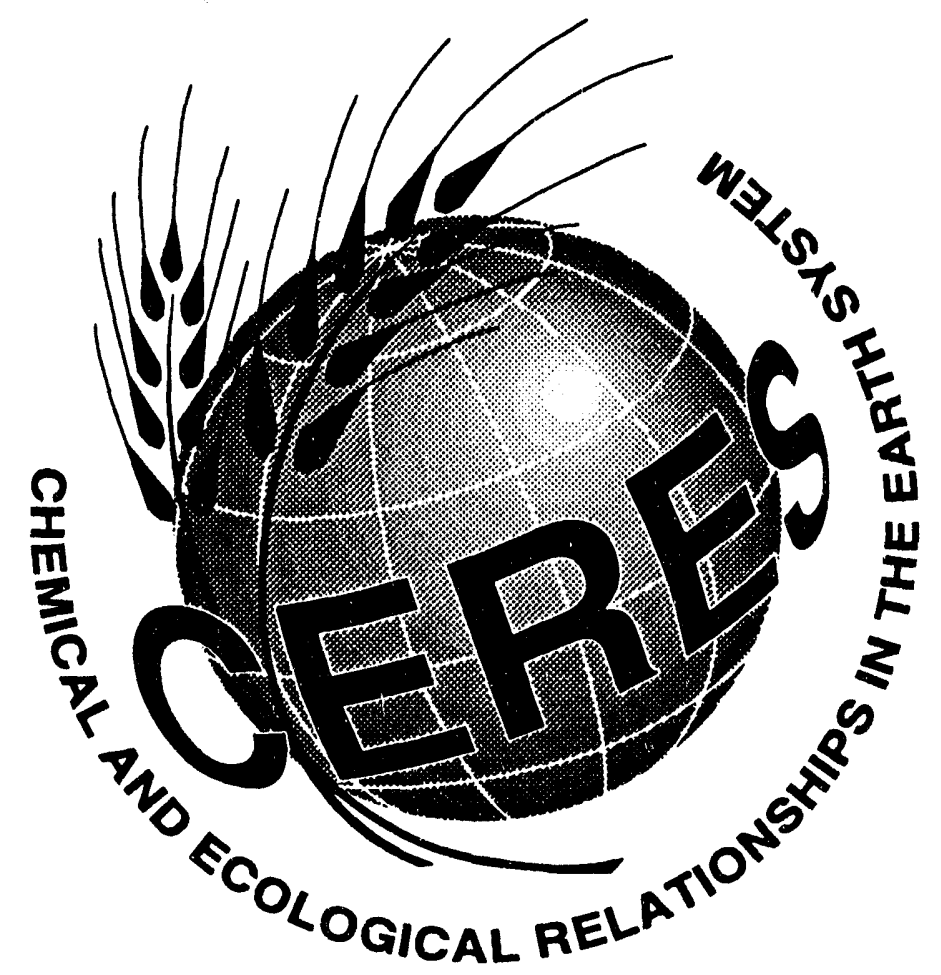

\section{Research Recommendations to the EPA in Support of Earth System Modeling Activities}

John J. Ambrosiano, William P. Dannevik, James Kercher, Norman L. Miller, Joyce Penner, and Douglas Rotman

Lawrence Livermore National Laboratory

August 1993 


\title{
Research Recommendations to the EPA in support of Earth System Modeling activities
}

\author{
John J. Ambrosiano, William P. Dannevik, James Kercher, \\ Norman L. Miller, Joyce Penner, and Douglas Rotman
}

Lawrence Livermore National Laboratory

Introduction

On July 13-14 of this year, the EPA Environmental Research Laboratory at Athens, Georgia convened a workshop to discuss the relationship of basic research activities sponsored by the laboratory to the emerging efforts to build global Earth System Models (ESMs). In response we have prepared a prioritized discussion of research topic areas that we recommmend be addressed in order to support ESM activities with a focus on chemical and ecological relationships.

In our view, one of the most important challenges in building an ESM incorporating the biosphere is the scaling of detailed biological and land surface processes to global dimensions and the sensitivity of such processes when viewed from that perspective. There are numerous aspects to this. We can only indicate general themes and highlight a few specific topics within the scope of this report. However, we think the subject merits considerable detailed attention. 
Bridging disparities in scale: "top-down" vs. "bottom-up"

Various processes related directly or indirectly to the Earth's climate represent a tremendous disparity of spatial scales. For example, the succession of vegetation under the influence of changes in climate or land use occurs at the community scale $\left(10 \mathrm{~m}^{2}\right)$ while general circulation models of the atmosphere (GCMs) operate at the global scale $\left(100 \mathrm{~km}^{2}\right)$. Scaling of landscape, community, and regional phenomena such that large scale areas accurately approximate underlying physical and biological processes is an area of top priority. The ecologist's view of the world is traditionally "bottom-up" whereas the climate modeler's view is "top-down". We believe in a pragmatic approach to understanding scale problems systematically from both directions.

A sensible first step in bridging the disparity in scales between ecological research and global modeling is to perform sensitivity analyses to economize the work of scaling by eliminating the need to scale up all processes. This could be achieved through the use of crude proxy models equipped with adjustable parameters. For example, an interactively coupled ocean - atmosphere - land surface - chemical transport ESM can be outfitted with a simple, highly parameterized terrestrial biospheric trace gas model. Formal sensitivity analyses using, for example, the Direct Decoupled Method [Milford, J. et al., Environ. Sci. \& Tech., 26, 1179 (1992)] or other approaches can be carried out to determine the relative importance of reaction rates, emission inventory parameters, spatial resolution, initial data, and a host of other characteristics. This information could then help to develop and prioritize an experimental process research program which would in turn have an important impact on ESM development and validation. 
Scaling requires an understanding of the functional dependence of fine scale processes and their nonlinear spatial and temporal variation with respect to functional changes. A "bottom-up" approach for upscale parameterizations is required and should be benchmarked by observations. This highlights the importance of an extended program of long-term ecological research (LTER) sites which could be chosen with modeling needs in mind. Sites should be chosen to balance the need for detailed information about diverse ecosystems against the cost of such intensive research sites.

New LTER sites should be representative of specific biomes for a range of characteristics. It would be useful to plan sites along gradients in moisture and nutrients. We also need statistical analysis along the scale-of-resolution gradient to tell us how things change along that gradient and how to characterize the distribution at each scale. This will help to design needed investigations at each scale. Such studies should at least give us an estimate of the number of samples needed to characterize processes ranging in scale from biome to continent.

It is important that scaling studies be coordinated with extensive data gathering (surveys) as well as intensive (field-site) process studies. Economy of effort may be possible through the use of sparse data statistical approaches [Bretherton, F. P., et. al., Deep-Sea Res., 23, 559 (1976)].

To relate information at different scales, techniques for spatial aggregation and disaggregation are needed. Aggregation may be viewed as weighted summation of subgrid processes. Determination of the weighting functions is the key. Whether this is to be done by lumping many small-scale features into a much smaller number of categories, or whether some statitstical 
technique should be used is an unresolved question. Disaggregation of large scale data down to the regional scale and finer would require histories of each parameter for each region or "similar" region.

\section{Understanding and modeling hydrology}

The second general topic area of prioritized importance is the understanding of hydrology and in particular soil moisture over the entire Earth. Hydrology couples atmospheric and land surface processes in an intimate and crucial feedback loop. Precipitation, evapotranspiration, and runoff drive surface and subsurface processes associated with productivity and decomposition. Soil moisture and temperature control biogeochemistry and needs to be well understood globally for an accurate assessment of surface and . subsurface fluxes.

Direct hydrological simulations require detailed data sets of characteristic vegetation, soil texture and elevation for individual watersheds. Obtaining a reliable data base would be an essential step before suitable hydrological transport modeling could be incorporated into an ESM framework.

Studies of several major watersheds have already begun [GEWEX/GCIP, Vorosmarty et al., Continental scale models of fluvial transport: An application to South America, Biogeochem. Cycles, Vol. 3, No. 3, 241-265, 1989]. The largest watersheds should be incorporated into the ESM framework as a first approximation. Following surface heterogeneity and sensitivity studies, an assessment of the resolution of streamflow could be made. Further studies would be required for a global simulation of water movement, especially in the Boreal regions. 
Statistical large scale hydrology may be parameterized as a function of a topographic soil index [Famigletti et al., Evapotranspiration and runoff from large land areas: Land surface hydrology for atmospheric general circulation models, Surveys in Geophysics, 12, 179-204,1992]. This statistical-dynamical approach neglects water transport. Nevertheless, it may be sufficient for calculating soil moisture over GCM subgrids. In any case, heterogeneity must be incorporated in order to maintain accuracy.

\section{Biological process studies and inventories}

A third area requiring attention is the effort to characterize basic attributes and processes in the terrestrial biosphere. Better inventories are needed of the initial conditions of vegetation state variables. Data sets are also needed for comparison to terrestrial model output. Specifically, we need more refined versions of vegetation type and land use than are now available. We also need global inventories of standing crops of biomass in vegetation expressed in terms of plant morphology (i.e., leaves, branch, stem, root, fine root) that are broken out by elemental content including carbon and nitrogen. The same is true for soils. Again, attention should be given to how distributions of such quantities change across scales of resolution.

In addition to biogeochemical process studies, there is a need to gather information on the response of vegetation to stresses and disturbances. We need to know about the fundamental characteristics of vegetation spread. This information should be gathered with consideration of variability within and between types. The particular stresses and disturbances that we have in mind are those associated with global change, i.e., temperature, precipitation, radiation, and $\mathrm{CO}_{2}$ changes. We need to develop an understanding of the 
interactions between these stresses and (1) community changes and (2) disturbances such as fire or insects. Stress response studies are needed to support portions of terrestrial submodels of ESMs that deal with vegetation response to climate change.

\section{Clouds, aerosol chemistry, and emissions}

A fourth area of importance is further studies of aerosols, clouds and aerosol/cloud/chemical interactions. Items of importance are the settling velocity of aerosols, effects of precipitation on aerosol distribution, wet and dry deposition of aerosols, and emissions from vegetation. There is a particular need for an evaluation of the sources of aerosols and any exchange between surface landscape characteristics of the Earth and atmospheric aerosols.

We also recommend detailed and updated inventories of hydrocarbon emissions from various sources. This applies to urban sources as well as those of biological origin. With respect to the biosphere, work needs to be done to determine the $\mathrm{CO}_{2}$ emissions for each biome as a function of controlling state variables. Hydrocarbon emissions from plant species are also necessary for a full assessment of ecophysiological feedbacks.

\section{A handbook of data sets}

As a final remark, we would like to suggest that EPA consider commissioning a thorough literature review in the areas discussed in this report with an aim to developing a handbook of data sets to be used in ESMs. Such an exercise would quickly show specific areas in which data was lacking. Such a handbook would reduce redundancy and be very important in planning. 


\section{Conclusion}

These recommendations represent our view based on discussions at the recent EPA meeting and our understanding of ESM needs and goals. They are by no means exhaustive.

A theme which emerges from our simple considerations is that some well-planned early parametric and sensitivity studies, using currentgeneration coupled Earth system model components, along with simplistic proxy models of terrestrial biospheric and biogeochemical processes, could furnish valuable information to help guide the development of a longer-term plan for research supporting ESM development. This theme is rooted in the premise that the importance of various ESM component processes can be fully assessed only from the perspective of a complete coupling of that process into the ESM context. That is, the question, "How well must a given process be modelled?" cannot be answered in isolation , but rather requires a careful blend of process research and coupled model studies.

\section{Acknowledgments}

This research was supported, in part, under interagency agreement by the US EPA Athens Environmental Research Laboratory. 

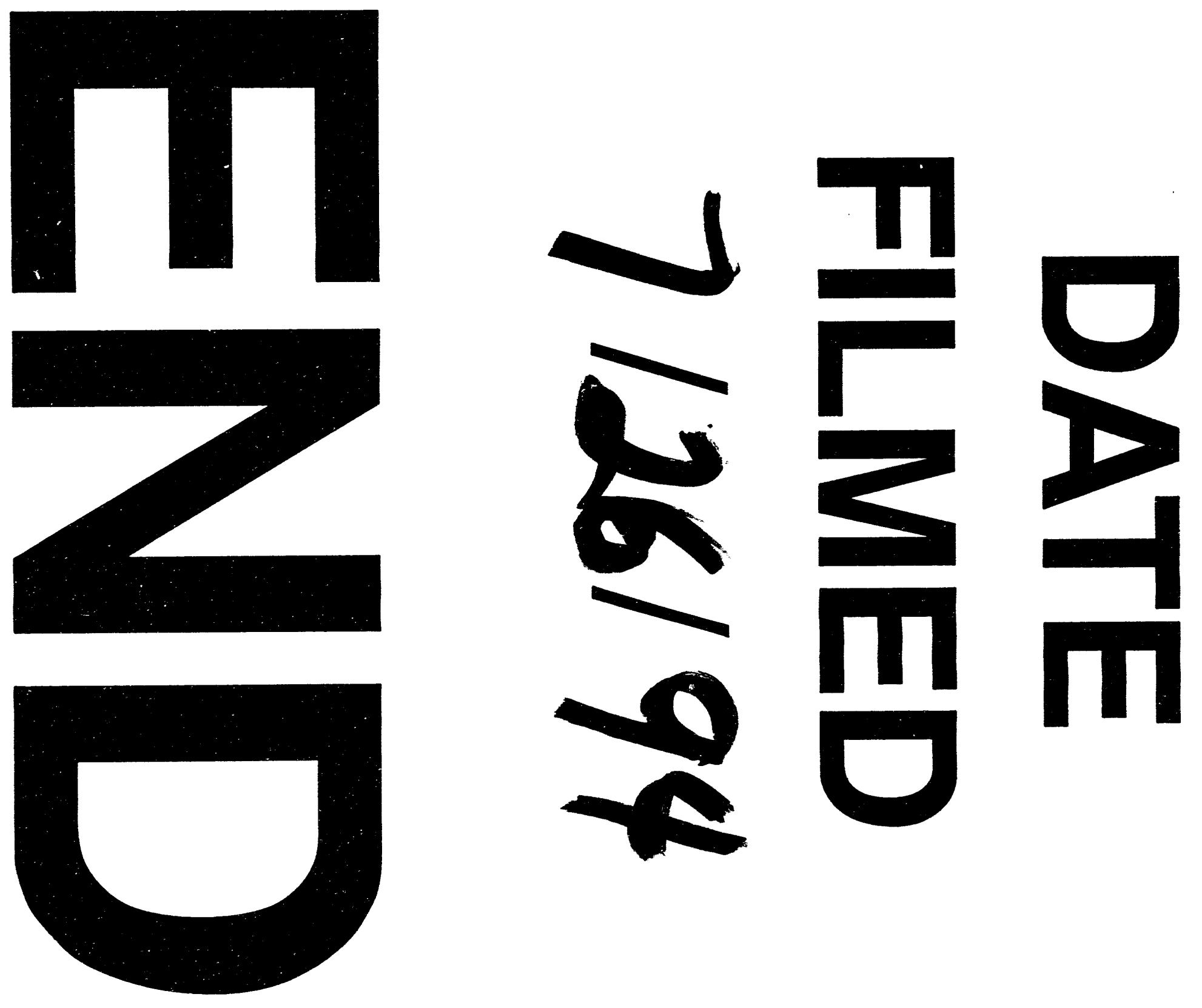
